\title{
What is the Difference Between a Definition and a Concept?
}

\author{
Michael F. Otte ${ }^{1}$, Luiz G. X. de Barros ${ }^{2}$ \\ ${ }^{1}$ University of Bielefeld, Bielefeld, Germany \\ ${ }^{2}$ Universidade Anhanguera de São Paulo (UNIAN), São Paulo, Brasil
}

Email address:

michaelontra@aol.com (M. F. Otte), lgxbarros@anhanguera.com (L. G. X. de Barros)

To cite this article:

Michael F. Otte, Luiz G. X. de Barros. What is the Difference Between a Definition and a Concept? Science Journal of Education. Vol. 4, No. 5, 2016, pp. 159-168. doi: 10.11648/j.sjedu.20160405.14

Received: September 21, 2016; Accepted: October 1, 2016; Published: October 27, 2016

\begin{abstract}
Definitions are formulated in order to draw conclusions and to solve technical problems. Tinkering around as long as it takes, until something halfway interesting comes out or can be concluded. Definitions are cognitive and communicative functions in the first place. Concepts, in contrast, are like continua relations and visions of possibilities. Mathematics seems to be that area of intellectual activity, where the difference between concepts and definitions and consequently the difference between seeing something on the one hand and calculating it on the other hand, gapes apart most strongly and widely. In this article, we discuss this difference from several viewpoints.
\end{abstract}

Keywords: Mathematics, Mathematics Education, Philosophy of Mathematics, Complementarity

\section{Introduction}

Evolutionary biologists would say, and they have to be considered experts in this matter, that concepts are like natural species. "I desire to point out," says Peirce, "that it is by taking advantage of the idea of continuity, of the passage from one form to another by insensible degrees, that the naturalist builds his conceptions" (Peirce, CP 2.646).

Mathematics seems to be that area of intellectual activity, where the difference between concepts and definitions and consequently the difference between seeing something on the one hand and calculating it on the other hand, gapes apart most strongly and widely (we shall come back to this problem in section VI.).

Philosophy is reasoning by means of concepts, says Kant (Kant, 1787, B 742) and Deleuze echoes him, "philosophy is the discipline that involves creating concepts" (Deleuze \& Guattari, 1996), while mathematics and science frame definitions and perform calculations or formal deductions. In mathematics, a concept is to be defined, as Moritz Schlick said, with respect to Hilbert's axiomatization of geometry, by the fact that certain conclusions can be drawn about it. And Schlick continues:

"There are no universal ideas ... It was Berkeley, who first pronounced this proposition with all necessary sharpness and it has since become a permanent possession of philosophy. ....
There are strictly speaking no general concepts, but there is a conceptual function ... The epistemological significance of the conceptual function is to designate. Concepts are signs, which however have not necessarily a reference, but whose reality consists in their mental functions". (Schlick, 1925).

Now, the essential fact, responsible for both, mathematics not being simply logic and straightforward algorithmic knowledge and humans not being just calculators or Sophists - "masters of rhetoric" -, or fixers of something arbitrary, refers to the necessity of idealization and generalization. So we must create new concepts and ideas, or ideal objects. To generalize means just this: to introduce new ideal objects. And to the complementarity of ideal and existent objects, or of meanings and things, corresponds a complementarity between mind and brain, or between an epistemological and an ontological subject (Klein, 2014).

Richard Rorty is considered the most important representatives of contemporary American philosophy and "Philosophy and the Mirror of Nature" (PMN) is Richard Rorty's most famous work. In this book, Rorty says, critically and with a derogatory undertone, "the distinction of the mental and the physical is parasitic on the universal-particular distinction rather than conversely" (Rorty, 1979, p. 31).

"There would not have been thought to be a problem about the nature of reason had our race confined itself to pointing out particular states of affairs-warning of cliffs and rain, 
celebrating individual births and deaths. But poetry speaks of man, birth, and death as such, and mathematics prides itself an overlooking individual details. When poetry and mathematics had come to self-consciousness when men like Ion and Theaetetus could identify themselves with their subjects the time had come for something general to be said about knowledge of universals. Philosophy undertook to examine the difference between knowing that there were parallel mountain ranges to the west and knowing that infinitely extended parallel lines never meet the difference between knowing that Socrates was good and knowing what goodness was. So the question arose: What are the analogies between knowing about mountains and knowing about lines, between knowing Socrates and knowing the Good? When this question was answered in terms of the distinction between the eye of the body and the Eye of the Mind, thought, intellect, insight was identified as what separates men from beasts" (Rorty, 1979, p. 38).

Rorty is right in believing that avoiding the hypostatic abstractions and ideal objects of mathematics might be a manner to reduce the cognizing subject to an information-processing machine. The subject is always to be conceived of in terms of the logic of its activity.

Looking at this very same connection between universals and the human self-more positively might provide, however, a glimpse on the "human spark":

"The human contribution to the miracle of life around us is obvious. We hit upon new ideas, on the fly, all the time and we have been performing this magic for, at least 50,000 years. We did not make galaxies, we did not make life. We did not make viruses, the sun, the DNA, or the chemical bond. But we do make new ideas. .... We are the origin of ideas ... The claim of this book is that the human spark comes from our advanced ability to blend ideas to make new ideas. Blending is the origin of ideas" (Turner, 2014).

The result of creative blending need not be presented explicitly in terms of definitions and conceptual language. Joseph M. W. Turner (1775-1851), for example, was one of the greatest painters of the $19^{\text {th }}$ century and an "inveterate" sketcher. There are between 10.000 and 20.000 individual sketches in the Turner request. "Often he would sketch a place even if he had sketched it several times before. By doing so he honed his unusual retentive memory, which is a crucial tool for an idealizing artist in as much as memory sifts the essential from the inessential" (Shane, 2014).

And it goes further! In his Snow Storm: Hannibal and his Army Crossing the Alps, first exhibited in 1812, Turner synthesized his studies of nature with historical knowledge. Turner saw parallels between Hannibal and Napoleon, and between the historic Punic War between Rome and Carthage and the contemporary Napoleonic Wars between Britain and France. In fact, the end of the war against Napoleon had enabled Turner to visit the Alps, in the first place and to study and capture their splendor.

Every act of creative behavior consists, in fact, in taking an adequate point of view in seeing an $A$ as a $B: A=B$ : a chair as a step-ladder, a hammer as part of a plumb line or a pendulum, a force as a vector, a mechanical operation as a calculation, a production line as a mathematical function, or more modestly, an apple as some eatable fruit, etc. etc. This is true for practical as well as theoretical contexts.

Metaphors serve to make one see something in a certain light or from a certain perspective.

The individual is thereby presented as a universal, as a prototype of some general idea and one might term that an "individual general". When the artist presents Napoleon as Roman emperor .... the locus of the metaphorical expression is in the representation - in Napoleon -as Roman-emperor rather than in the reality represented. The object of the metaphor is, as was said the power, legitimate authority and dignity emanating from a roman emperor and Napoleon is to be seen as an incarnation of that power and dignity.

When a small boy says "I am a tiger", this is done in the same spirit.

\section{The Notion of Complementarity}

William Byers takes the riddles of equality and difference to affirm that ambiguity is essential to mathematics. "Now one might think that mathematics is characterized by the clarity and precision of its ideas and, therefore, that there is only one correct way to understand a given mathematical situation or concept. On the contrary, I maintain that what characterizes important ideas is precisely that they can be understood in multiple ways; this is the way to measure the richness of ideas" (Byers, 2007, p. 23).

What Byers calls ambiguity we have called complementarity (Otte \& Steinbring, 1977 and Otte, 1994, 2003).

We provide here a more or less precise definition of the notion of complementarity in terms of the distinction between sense and reference of signs.

Even a logician like Frege considered the complementarity of sense and reference, or concepts and objects as fundamentally important. Following Frege an 'equation' $A=$ $B$ is commonly interpreted as saying that $A$ and $B$ are different intensions of the same extension, or different designations of the same object. Both terms $A$ and $B$ have the same reference, while the sense or the mode of presentation is different. In Frege's famous essay on Sinn und Bedeutung, the author quotes some examples from elementary geometry. Frege writes:

"Let $a, b, c$ be the lines connecting the vertices of a triangle with the midpoints of the opposite sides. The point of intersection of $a$ and $b$ is then the same as the point of intersection of $b$ and $c$. So we have different designations for the same point, and these names ('point of intersection of a and b'; 'point of intersection of $b$ and c') likewise indicate the mode of presentation, and hence the statement contains actual knowledge". (Frege, 1969, p. 40).

Frege obviously understood $A$ and $B$ as descriptions, rather than as denotations and that marks an important distinction between mathematics and logic. Since Frege uses $A$ and $B$ merely to identify a particular individual descriptively, these 
signs can be replaced with others that have the same referent, whereas an attributive use of a representation cannot, for reasons of cognitive or emotional dynamics, for example. Frege claims, in fact, that mathematicians define neither concepts, nor their contents, but rather their extensions.

"For the mathematician, it is no more correct and no more incorrect to define a conic section as the circumference of the intersection of a plane and the surface of a right circular cone than as a plane curve whose equation with respect to rectangular co-ordinates is of degree 2 . Which of these two definitions he chooses, or whether he chooses another again, is guided solely by grounds of convenience, although these expressions neither have the same sense nor evoke the same ideas" (Frege, quoted after, Dummett, 1991, p. 32).

Frege is right from his logical point of view, being focused exclusively on the "context of justification" and ignoring the context of discovery. It is, in fact, one thing to retrace the historical origins, the psychological genesis and development, the socio-politico-economic conditions for the acceptance or rejection of scientific theories; and it is quite another thing to provide a logical reconstruction of the conceptual structure and of the testing of scientific theories.

However, we cannot understand, nor even discuss some fundamental questions about the nature of mathematics, - like the relationship between empirical observation and mathematical deduction, which was constitutive for the development of modern mathematics and science, or the question of the analytic/synthetic distinction, which pervades all reflections about the nature of mathematics since Antiquity, - if we do not try to relate historical development to logical analysis and vice versa.

Lakatos paraphrasing Kant writes: "The history of mathematics, lacking the guidance of philosophy, is blind, while the philosophy of mathematics, turning its back on the most intriguing phenomena in the history of mathematics, is empty" (Lakatos 1970, p. 135).

In addition, one should mention the following. Firstly, with respect to the growth of knowledge, it seems very relevant indeed which definition is chosen, which perspective is taken, or how a problem situation is represented. How a mathematician defines something, a conic section, for instance, to take Frege's example, is certainly important. Two concepts $\mathrm{A}$ and $\mathrm{B}$ are not the same, even if contingently or necessarily all $A$ 's are $B$ 's and vice versa, because different concepts help to establish different kinds of relationships and thus influence knowledge development in different ways. Two concepts could be extensionally equivalent and yet could be different, and might function differently, within a certain context and with respect to the growth of knowledge.

We always use our words and symbols attributively as well as referentially. Frege, in fact, cannot describe the relation of $A$ and $B$ as parts of $A=B$ without reference to an object. One may however introduce a new concept, "center of gravity" in the above case, and then one might go one to derive new insights from that.

The problem is that Fregean senses are dependent of reference, and they seem to be somewhat the result of an ad hoc maneuver. "If sense is reducible to reference within the theory of reference, it is not immediately clear why the distinction between sense and reference should survive" (Katz, 2004, p.12).One might therefore suspect that mathematics - at least considered from a dynamical or genetic perspective - is characterized by a complementarity of the intensional and extensional aspects of its representations. Sense and reference are distinguished by their complementary roles in the development of knowledge.

We may, for example, verify a numerical formula, like $a b=$ $b a$, either syntactically or by means of combinatorial diagrams (Greene \& Knuth, 1981). Already Leibniz considered algebra as a branch of combinatorics, as he points out, for example, in a letter to the Marquis de L'Hôpital (1661-1704) in 1692, and not as generalized arithmetic. And he did so to emphasize the iconic character of algebraic diagrams.

"It may seem at first glance that it is an arbitrary classification to call an algebraic expression an icon .... but it is not so. For a great distinguishing property of the icon is that by the direct observation of it, other truths concerning its object can be discovered than those which suffice to determine its construction" (Peirce, CP, 1.279).

So algebraic formulas and diagrams have two aspects, a logical-linear and a visual-ideographic.

The whole discussion about the analytic/synthetic distinction since Kant or Bolzano and Frege circles around this difference between concepts (universals) and objects (particulars). Bolzano recognizes Kant's insistence on the analytic/synthetic distinction as important and he drew a sharp a distinction between concept and object, like Kant. And on this distinction the other one between analytic and synthetic propositions is crafted, because both Kant, as well as, Bolzano, became aware of the errors of the traditional notion of a concept as something established by abstraction, wherefrom results the law of inverse relation between content and extension of concepts. Bolzano, refusing this law of inverse relationship, writes:

"If I am so fortunate as to have avoided a mistake here which remained unnoticed by others, I will openly acknowledge what I have to thank for it, namely it is only the distinction Kant made between analytic and synthetic judgments, which could not be if all of the properties of an object had to be components of its representation" (Bolzano, $1837, \S 120)$.

A proposition is obviously synthetic if its predicate contains a characteristic of the object, which is not already part of the presentation of the subject of that proposition.

The analytic/synthetic distinction lies at the heart of Kant's Critique of Pure Reason. How are synthetic judgements a priori possible at all? This is the central question Kant sought to answer in his Critique of Pure Reason. Unlike his predecessors Leibniz and Hume, Kant maintained that synthetic a priori judgments not only are possible but actually provide the basis for significant portions of human knowledge, like mathematics and the exact physical sciences.

Kant presents the following example: "When I say, All bodies are extended, this is an analytical judgment" (Kant, B 
11). The sentence is analytic, because I cannot but imagine bodies unconsciously and inevitably as extended.

Bolzano was not any more concerned with epistemology, but with science and mathematics as a cultural and logical phenomenon. Bolzano concentrates on science as a reality sui generis and tries to outline the requirements of a theory of knowledge representation and conceptual reasoning. The first thing a sign or representation must fulfill, in order to function as a sign at all, is consistency and Bolzano bases his doctrine of science exactly on the principle of consistence.

He replaces Descartes' "Cogito ergo sum" by the affirmation

Bolzano consequently constitutes a kind of linguistic ontology by hypostatizing linguistic sense and thereby conceiving of a "third world", beyond the world of physical objects or physical states and the world of states of consciousness. Popper, who had coined this term, "third world", had acknowledged inspiration from Bolzano in his search for an "objective epistemology" (Popper, 1972, p. 106).

Bolzano called his logic a "doctrine of science" (Wissenschaftslehre (WL)) and he critizised those, who have considered logic to be the science of how humans think. "One is inclined to feel that it is too little for a doctrine of science (Wissenschaftslehre) not to want to rise oneself beyond the consideration of the laws which bind only our thinking, rather than proceed to the propositions and truths in themselves, which would be the next higher thing" (Bolzano, 1837, §16).

Bolzano recognizes Kant's insistence on the analytic/synthetic distinction as important, but turns it into a question of the form of a sentence. He possibly identified Kant's example as of the form, "(B cum $\mathrm{x}$ ), has $\mathrm{x}$ ". Consequently, Bolzano defines:

"If there is a single representation (eine einzige Vorstellung) in a proposition which can be arbitrarily varied without disturbing its truth or falsity ... then this character of the proposition is sufficiently remarkable to distinguish it from all others. I permit myself thence to call propositions of this kind, borrowing an expression from Kant, analytic, all others, however, synthetic propositions" (Bolzano, 1837, §148).

The sentence, " $\mathrm{x}$ is mortal" is synthetic, if God exists, for example, and it is analytic otherwise.

\section{About Philosophy of Mathematics}

A number of prominent people in the field (E. Musk, N. Bostrom, S. Hawking, B. Gates, etc.) are describing Artificial Intelligence (AI) as "summoning the demon" (The Economist, May $\left.9^{\text {th }}, 2015\right)$. Hawking even fears that robots might wipe out homo sapiens from the face of the earth in an evolutionary competition.

In any case, the combination of a growing abundance of data and rising processing power really seems about to take over things. When did this development start? Perhaps with the Scientific Revolution of the $17 / 18^{\text {th }}$ centuries already!?

Hans Reichenbach, member of the Vienna Circle logical empiricists, indicates that the connection between observational data and mathematics was essential to the new sciences:
"The mathematical method has given modern physics predictive power. Whoever speaks of empirical science, should not forget that observation and experiment were only able to establish modern science, because they could rely on mathematical deduction. ... A mere collection of observational facts would never have led to the discovery of the law of attraction. Mathematical deduction in combination with observation is the instrument that accounts for the success of modern science. The application of mathematical method has found its most conspicuous expression in the conception of causality that was developed because of the ... physics of Newton. Since it was possible to express physical laws in the form of mathematical equations, it appeared as though physical necessity could be transformed into mathematical necessity" (Reichenbach, 1951, p. 102).

Isaac Newton, the greatest scientist of the time, wanted to end the metaphysics governed ideal of science and wanted to explain nature in mathematical terms, rather than speculating about the essence of things. But he thought that the relationship between mathematics and natural philosophy be methodological rather than ontological (Otte \& Lenhard, 2010). The Scientific Revolution unfolded in quite a positivistic spirit according to which the rationality of science is a consequence of its method. The certainty of mathematical method was just inspiring the Scientific Revolution. It "begins the old hierarchy of the sciences after the aspect of the necessity and excellence of the object to be replaced by the order according to the certainty of knowledge« (Schüling, 1969).

And when Leibniz burst upon the intellectual scene in Europe in the early 1670 s, it was as an enthusiast of the new Mechanical Philosophy. However, to Leibniz Newton's methodological approach to natural philosophy was not sufficient, to provide real intelligibility. The universe was to be seen as constituted in God's mind by ideas and laws that remain valid in all possible worlds. Like Plato, Leibniz could not tolerate a world without reason and human destination, as his troubled discussions with Spinoza and Newton show (Stewart, 2006, p. 241). Leibniz searched for a thoroughly human and intelligible world, in which even contingent facts would find their explanation, hence his principle of sufficient reason. Even the contingent truths of empirical science required their proofs - infinite proofs, based on the Principle of Continuity.

To Leibniz the Principle of Continuity was something ideal. The real world of existing substances was to be considered as composed of distinct elements (substances). These substances are to be identified by their complete concepts, according to the principle of the Identity of Indiscernibles, the second fundamental principle of his philosophy (this principle is in fact the opposite of the axiom of extension on which modern mathematics is founded).

Leibniz has created our modern concept of mathematical proof by understanding that a proof is valid by virtue of its form, not by virtue of its content. This does not imply, however, contrary to a claim made by Russell (Russell, 1919, p. 178) that Leibniz's philosophy rests solely on his logic, 
because Leibniz assumed a one-one correspondence between concepts and objects. As in his view all things in this world are constituted by the concepts corresponding to them in God's mind, and to try and identify them amounts to an infinite analysis of the respective concept. Thus, it is due to our limitations that some truths appear to be contingent and others necessary.

Everybody knows analytically that Hamlet's mother cannot have been a man, but nobody can know a priori and analytically what the color of her eyes might have been. Leibniz would consider this due to the fact that we, the human beings, unlike God, do not have the complete concept of "Hamlet's mother" at our disposal. We do not know all the details of her existence, nor the complete story of her life. In mathematics, things are different, because mathematical concepts are simpler. In mathematics, the intensions of concepts are just finite definitions.

But what about the continuum? Even if the composition of the continuum is understood as a purely mathematical problem - that of whether the line, for instance, is composed of points, or numbers, or perhaps neither, the "complete concept", that is, the decimal number determining a certain point, for example, would have to contain an infinity of digits, as a rule. And in the majority of cases the decimal representation cannot be computed, as Cantor had shown. Such infinite proofs are required to establish the contingent truths of empirical science and only God's infinite mind could accomplish the task.

Hypotheses non fingo, Newton had famously said. "In experimental philosophy... particular propositions are inferred from the phenomena, and afterwards rendered general by induction" (Newton, 1729).

Therefore we come to ask, how are we to justify induction? How does induction succeed in its aim to generalize from the individual to the universal? The answer would again indicate principles, like the Continuity Principle or might consist in postulating a law of "Uniformity of Nature".

If we endorse an evolutionary realism and if we believe in a similarity of mental and natural processes we were to think about the framing of new concepts roughly, as the biologists think about the evolution of new species.

The relations between continuity, variation and possibility influence all theories of evolution. Ernst Mayr, sometimes considered the "Darwin of the $20^{\text {th }}$ century", for example, distinguishes between "typological thinking (essentialism)", founded, as he says, by Plato, and "population thinking", which he ascribes to Darwin. As an example of essentialism, he cites the famous "general triangle" from geometry. With respect to population thinking, he writes, "What we find among living organisms are not constant types, but variable populations ... Within a population ... every individual is uniquely different from every other individual". In addition, if the differences between individuals become sufficiently large, two species might suddenly break away where there had been just one before. Darwin's "basic insight was that the living world consists not of invariable essences (Platonic classes), but of highly variable populations. And it is the change of populations of organisms that is designated as evolution"
(Mayr, 2001, chapter 5).

Peirce is perhaps the most compelling example of a late $19^{\text {th }}$ century thinker who sought to apply Charles Darwin's suggestion of evolution to other areas of science. Peirce considers, like Mayr, the explanation of growth and diversification as essential to a theory of evolution. Any increase in variety points to spontaneity as an effective agency, because law never produces diversification (Peirce, CP 1.174). So evolution theory must explain not only the phenomena, but also general facts, like natural laws or Platonic essences. So even the world of universals is changing!

Even theoretical mathematics cannot develop on a purely formal or algorithmic basis, as Gödel's incompleteness theorems have shown. Charles Peirce, for example, affirms that in the more involved cases of mathematical reasoning a "theorematic deduction" is required, which "performs an ingenious experiment upon a diagram, (that is, on the image of the premisses, our insertion) and by continuously modifying the diagram and observing the changes as well as the invariants upon continuous modification, he might then try and frame a hypothesis and formulate a theorem (Otte, 2003). This modification depends on the abductive introduction of a new idea according to which the diagram is then modified render the conclusion more or less obvious.

"What I call the theorematic reasoning of mathematics consists in introducing a foreign idea, using it, and finally deducing a conclusion from which it is eliminated. ... The principal result of my closer studies of it has been the very great part, which an operation plays in it, which throughout modern times has been taken for nothing better than a proper butt of ridicule. It is the operation of abstraction, in the proper sense of the term, which, for example, converts the proposition Opium puts people to sleep into Opium has a dormitive virtue ... I am able to prove that the most practically important results of mathematics could not in any way be attained without this operation of abstraction. It is therefore necessary for logic to distinguish sharply between good abstraction and bad abstraction" (Peirce, NEM IV, p. 42, 49).

\section{The Principle of Continuity}

Our empirical contacts with reality seem limited to the observation of so-called facts, that is, are limited to what we can observe and distinguish locally. However, philosophy and science are concerned with laws of nature and as these laws establish relations between universals, rather than particular existents, we have to generalize.

Neither the mathematical axioms nor the laws of nature can be understood reasonably as consisting of an infinite conjunction, along the lines: "the stone 1 is falling from the tower", "the stone 2 is falling from the tower", "the stone 3 is falling ....", etc., etc.. Galileo and all natural philosophers since Aristotle have therefore maintained that a Principle of Continuity is essential.

Aristotle is most often regarded as the great representative of a logic and mathematics, which rests on the assumption of the possibility of clear divisions and rigorous classification. 
"But this is only half the story about Aristotle; and it is questionable whether it is the more important half. For it is equally true that he first suggested the limitations and dangers of classification, and the non-conformity of nature to those sharp divisions which are so indispensable for language $[. .$.$] "$ (Lovejoy, 1964, p. 58).

Aristotle thereby became responsible for the introduction of the principle of continuity into natural history. To generalize and extend factual knowledge requires an act of faith in the Continuity of Nature. The Principle of Continuity has been of fundamental importance to all the exact sciences, including mathematics. Continuity, writes Peirce, with an eye on Aristotles, is "nothing but a higher type of that which we know as generality. It is relational generality" (Peirce, CP 6.190).

Aristotle's basic intuition, "seems to be that nothing can be linked to anything else without a mediating relation", that is, without a third entity (Rucker, 1982, p. 147). Our talking of a healthy or good person only makes sense in relation to the sick and bad man. In consequence, the individual does not exist without the universal or general and the latter is conceived of in relational terms rather than predicative ones. The universal and thus the continuum has preference over the particular and individual and space and time are no sets of points or instances (Aristotle, 2015, book VI, chapter 9).

As regards mathematics, Hilbert himself has pointed out that the free variables occurring in the axiomatic statements are of this type of generality.

"For example, the statement that if $a$ is a numerical symbol, then $a+1=1+a$ is universally true, is from our finitary perspective incapable of negation. We will see this better if we consider that this statement cannot be interpreted as a conjunction of infinitely many numerical equations by means of 'and' but only as a hypothetical judgment which asserts something for the case when a numerical symbol is given. From our finitary viewpoint, therefore, we cannot argue that an equation like the one just given, where an arbitrary numerical symbol occurs, either holds for every symbol or is disproved by a counter example" (Hilbert, 1964, p. 91).

The general appears in two forms as predicative generality on the one side and as relational generality or continuity, on the other side. We have mentioned this above when reporting on Aristotle (section II.). Take color as an empirical example. Redness or red is a predicate that applies to many things. But it is a universal too, a color, an ideal object that appears in quite a number of shades. In the first case red appears as a propositional function, " $\mathrm{x}$ is red" in the second case the generality derives exactly from the lack of complete determination.

Bertrand Russell describes the difference from his logical and formal point of view that is ignoring the reality of the continuum. Russell writes:

"I met a unicorn is a perfectly significant assertion, if we know ... what is the definition of these fabulous monsters. Thus it is only what we may call the concept (or the definition, our insertion!) that enters into the proposition. In the case of 'unicorn', there is only the concept: there is not also, somewhere among the shades something unreal, which may be called 'a unicorn'. Therefore, since it is significant, though false to say, 'I met a unicorn', it is clear that the proposition, rightly analyzed, does not contain a constituent 'a unicorn', though it does contain the concept 'unicorn"” (Russell, 1919, Chapter XVI).

Peirce in contrast to Russell recognizes the continuum as real and as a realm of real possibilities. A general, as the "infamous" general triangle is a free variable that can be further be specified as need might be. When we conceive of generalization as the introduction of variables, we can realize the difference between predicative generality and continuity by observing that in discrete mathematics and computer science variables are mere placeholders, while in continuous mathematics and the empirical sciences variables are objectual, "general", that is, incompletely determined objects. In a proposition like "an apple is a fruit", it would be unnatural to interpret "an apple" as a placeholder, because this presupposes that we have given individual names to all the apples in this world (Quine, 1974, chapter III).

There are, however, philosophers, who claim that theoretical concepts which are not explicitly defined are unnecessary or even undesirable in mathematics or science. Some formulated their position in terms of a so called "theoreticians dilemma" (Tuomela, 1973, p.3). The dilemma can be stated in the following form:

"1. Concepts either serve their purpose or they do not serve it.

2. If they do not serve it, they are dispensable.

3 . If the serve their purpose they establish relationships among observables or between explicit propositions.

4. If they establish such relationships, the same relationships can be established without theoretical concepts and the latter are therefore dispensable!"

The logical empiricists, like Carl G. Hempel (1905-1997) wanted foremost to distinguish linguistic sense from nonsense and they were not interested in the so-called "context of discovery". Considering mathematics as essentially based on the principle of non-contradiction and thus considering mathematical knowledge as essentially logical knowledge comes out as the result of a strict separation between the context of discovery as opposed to the context of justification. The claim that there is a distinction between discovery and justification, together with the claim that only the latter is the legitimate province of the philosophy of science, was one of the cardinal principles of the Vienna Circle.

Under such premises, it seems important, indeed, to have jurisdiction over language and definitions. For example, the state as legislator exerts an important sovereignty of definition! Recently Justice Potter Stuart from the Supreme Court of the United States became desperate, however, when trying to give a legal definition of pornography. "I know it when I see it!", he exclaimed. A concept is a continuum and a definition tries to render it in distinct terms.

And if somebody is defending in a discussion with a professor of philosophy of the analytical stripe that something is impossible, the professor might answer with a show of disdain: "Of course - granted your definitions.... Your view is 
an arbitrary fiat, it is a matter of semantics, it is logically true but not factually true".

This point of view presents us with the following choice: If your statement is proved it says nothing about that which exists; if it is about existents, it cannot be proved. Formal mathematics and logic speak, according to analytic philosophy, not about objects. "Mathematics and logic say nothing about objects, of which we want to speak, but deal only with the way we talk about objects" (Hahn, 1988, p. 150).

The manifesto of the Vienna Circle of 1929 quotes the famous phrase of Protagoras: "Man is the measure of all things". In philosophy and science, this attitude leads to the expulsion of ideas and of all complex symbols. There should remain no "deep meanings" and everything was to be plain surface and perceivable form.

The shrinking of the truth-possibilities on data that can be communicated with compulsive certainty, leads to the subjectification of purposes and meanings. And the subject considered here, is reduced to the computer, to a data processing machine. There is in fact another remarkable trait of mathematical language, which did fascinate Leibniz already it makes understanding superfluous. "Frequently, students are instructed that they must think about things in order to understand them and to move forward. But in some sense, the greatest progress of human thought have incurred as a result that we have learned to do things without thinking" (Barrow, 1992, p. 3, our translation).

In a similar vein Leibniz said: "The only way to rectify our reasonings is to make them as tangible as those of the Mathematicians, so that we can find our error at a glance, and when there are disputes among persons, we can simply say: Let us calculate [calculemus], without further ado, to see who is right" (The Art of Discovery).

\section{Mathematics as a Language}

That types of production do profoundly influence all ways of social and cultural life seems a commonplace. But differences in the mode of communication are often as important as differences in the mode of production, for they involve developments in the creation and storing of human knowledge. Although they are not directly productive, they could form an indispensable integrative part of the system of production. Even if one were inclined, like Kant, to consider mathematics as an activity, rather than as a language, one would have to admit that mathematical activity is not just a simple process, occurring hic et nunc, but is a system of relationships between motifs (problems) and means. And this notion of "means" of activity must be seen in a wider social context and as shifting and variable through history. Already in 1620, Francis Bacon (1561-1626) wrote that printing, gunpowder, and the compass were the three inventions that "have changed the appearance and state of the whole world."

So it seems that the instruments and types of representation punctuate intellectual history. Changes with respect to the instruments of production and communication seem primarily responsible for the "Scientific Revolutions" (Kuhn, 1996), while ideas and basic concepts provide continuity. Kuhn had emphasized the discontinuity of scientific development and Feyerabend further radicalized the discontinuous character. He sought to downgrade the importance of empirical arguments by suggesting that aesthetic criteria, personal whims and social factors have a far more decisive role in the history of science than rationalist or empiricist historiography would indicate. And Edgar Zilsel had pointed out that already in the 16th century there were three different social groups and the associated three intellectual traditions that came together in producing the new cultural climate of the Renaissance:

1. the artists, engineers, medical doctors and practical mathematicians or reckoners

2. the humanists of the Renaissance (located at courts and universities)

3. the scholastics of the monasteries and the Church.

Philosophers, including Kuhn, have undervalued a major source of transformative developments, namely, material culture, specifically the development of new instruments. Are paradigm shifts, in the sense of Fleck, Kuhn or Feyerabend more dependent on technologies and material conditions than of the ideas. Conceptual meanings are much more ambiguous and infinitely more versatile than tools.

I have experienced in my life two major technological upheavals. Once the mechanization of agriculture and the simultaneous motorization of society in the wake of the oil boom and, secondly, the computer revolution. But while I have mastered the first, because I was still young enough at the time, I find the second actually repugnant.

While I have many years assembled and disassembled motorcycles, cars and other engines, I find the fiddling around with the computer or the smart phone a disgrace and a load. I have heard that the famous mathematician G. Hardy from Cambridge held a deep distrust for all mechanical contrivances, including even fountain pens, such that he was not able to appreciate any of the work of his colleague A. Turing.

The mechanization of agriculture brought physically and emotionally many reliefs to me and to many others. Tractors were expensive, even though it were the 12-16 year old boys who steered and worked with them, because the grownups did not get accustomed to the new machinery. Before that time, all work in the fields and in the woods had been done with horses. The first combine harvesters were still pulled by 6-8 horses. To manage and maneuver them around already represented an art, since horses have their own ideas and their own likes and dislikes. I have always loved horses and grew up with them, but working with them was very demanding and often physically demanding for a boy like me.

In other words, while man constantly receives new and revolutionary ideas and develops them, while intellectual creativity always fights against restrictions, people remain somehow permanently connected to the physical, geographical and technological context in which they have grown up from childhood. Only with the demise of one generation and the arrival of a new one technological revolution, become reality. Max Planck has said the same 
thing about scientific revolutions. "An important scientific innovation rarely makes its way by gradually winning over and converting its opponents: it rarely happens that Saul becomes Paul. What does happen is that its opponents gradually die out and that the growing generation is familiarized with the ideas from the beginning" (Planck, 1936, p. 97).

Turing had reacted against the skeptical arguments, challenging the claim that computers might someday think, by demanding that these people should define exactly what human thinking is. Because everything that could be defined precisely, could be implemented in a machine. Turing's opponents are actually juggling between substantialism and functionalism.

On the one hand, thinking is seen as an internal experience. That someone thinks is accessible only to this someone himself and his introspective intuition. As Descartes said: Cogito ergo sum! One cannot describe thinking and feeling, only experience it. Turing answered, that such a view implies that nobody else need to care.

When speaking about the thinking of the computer, on the other hand, one has of course, to accept that a computer simulation of thinking presupposes a theoretical description of it. However, since the description of something is of a different logical type of that something - the menu is not the meal - it is automatically shown by this categorical type jump that computers can neither think nor feel. The distinction between subject and object is made from the functional on knowledge and thinking.

There is the famous thought experiment of the "Chinese room" proposed by John Searle (Searle, 1980). It is directed against the idea that the ability for handling certain translation tasks would prove the intelligence of the operating system. For Searle, even a perfect system for automated translation would not prove anything like the system acts intelligently. Searle wanted to separate intelligence from any feat an automated system could achieve.

Where is communicative behavior, there is also a subject, Turing would say. Searle might respond that the human subject is not identical with the entirety of its technically identifiable characteristics and behaviors that it is of a different categorical type. It is a universal, not a particular existent. The problem is, that both are right somewhere.

Now intuition is, in fact, not discursive, it is very fragile and cannot be explained nor circumscribed and modified. If you do not get it, things become complicated because no explanation or commentary will make you see matters the way you should. This fact has a reverse side! Suppose I have found a proof for some mathematical theorem, which after having checked out the argument of the proof systematically is now intuitively completely clear to me.

"Suppose that a great authority announces that there is something wrong with the argument. In that case, my experience upon checking over the argument may be quite different from what it was before this announcement was made. Just as before, I find that the argument appears to be correct; only this time I do not accept it as being correct"
(Stolzenberg, 1980).

This remains true even if I cannot find fault with my argument. The distinction between being correct and merely appearing to be correct is the same as that between seeing something or having an idea and merely following a rule or a chain of formal conclusions.

During the 1940ties, Norbert Wiener and John von Neumann were both asking themselves what the new scientific discipline of computer science would have to look like in order to be able to advance the computer to a new general-purpose instrument. Norbert Wiener, conceived of simulation as imitating the behavior of a complex system with a computer model. Here, the technical construction plays a major role, enabling the use of black box approaches that explicitly abandon any ontological stance.

Von Neumann disagreed very much with Wieners approach of statistical modelling. He is alluding to Turing's findings on computability and the universal Turing machine (which corresponds fairly precisely to the independently developed computer) as well as to the neural mechanism of "firing" as soon as a critical input threshold is reached. Networks of neurons can show universal behavior, that is, generate random patterns. It is precisely because of the performance and adjustability of the simulation model that it is impossible to learn anything about true mechanisms from a successful imitation of behavior patterns ("functioning"). Von Neumann thus proposed that the virus should replace the human nervous system as the object of research.

"Now the less-than-cellular organisms of the virus or bacteriophage type do possess the decisive traits of any living organism: They are self reproductive and they are able to orient themselves in an unorganized milieu, to move towards food, to appropriate it and to use it. Consequently, a "true" understanding of these organisms may be the first relevant step forward and possibly the greatest step that may at all be required.

I would, however, put on "true" understanding the most stringent interpretation possible: That is, understanding the organism in the exacting sense in which one may want to understand a detailed drawing of a machine-i.e., finding out where every individual nut and bolt is located, etc." (Masani, 1990, p. 245).

It is exactly the same type of thinking we have seen in Mayr or Peirce. And Gregory Bateson the eminent anthropologist and semiotician writes:

"We shall note elsewhere in this book that there is a deep gulf between statements about an identified individual and statements about a class. Such statements are of different logical type, and prediction from one to the other is always unsure. .... In the theory of history, Marxian philosophy insists that the great men who have been the historic nuclei for profound social change or invention are, in a certain sense, irrelevant to the changes they precipitated. It is argued, for example, that in 1859, the occidental world was ready and ripe (perhaps overripe) to create and receive a theory of evolution that could reflect and justify the ethics of the Industrial Revolution.

From that point of view, Charles Darwin himself could be made to appear unimportant. If he had not put out his theory, 
somebody else would have put out a similar theory within the next five years. Indeed, the parallelism between Alfred Russel Wallace's theory and that of Darwin would seem at first sight to support this view. ......

But, of course, it does matter who starts the trend. If it had been Wallace instead of Darwin, we would have had a very different theory of evolution today. The whole cybernetics movement might have occurred 100 years earlier as a result of Wallace's comparison between the steam engine with a governor and the process of natural selection" (Bateson, 1980).

It does matter, but not in that definite one-sided way. Bateson gives too much room to chance, because he does not believe in historical objectivity. However, the processes of generalization never stops. Peirce would say, "the one primary and fundamental tendency of mental action is the tendency to generalize" (Peirce, CP 6.21; CP 1.82). Peirce's Synechism insists upon the idea of continuity as of prime importance in philosophy" (Peirce, CP 6.169), rejects an absolute difference between our inner and outer world as being one of kind, but considers it instead as a difference only of degree. Material and psychical phenomena are not entirely distinct (Peirce, NEM 4, XVII; NEM 4, 355; CP 5.45; CP 8.261).

\section{References}

[1] ARISTOTLE, Physics, book VI, chapter 9. Acessed on May, 25, 2015 in: http://classics.mit.edu/Aristotle/physics.6.vi.html

[2] BARROW, J., 1992. Perche il mondo e matematico?. Roma: Editore Guis.

[3] BATESON, G., 1980. Mind and Nature. Toronto: Bantam Books, Toronto.

[4] BOLZANO, B., 1837: Wissenschaftslehre (WL), 4 vol., Sulzbach. Republication by W. Schultz, Leipzig 1929-31.

[5] BYERS, W., 2007. How Mathematicians Think. Princeton UP.

[6] DELEUZE, G. \& GUATTARI, F., 1996. What is Philosophy? Columbia University Press.

[7] DUMMETT, M., 1991. Frege. Cambridge, MA: Harvard University Press.

[8] FREGE, G., 1969. Funktion, Begriff, Bedeutung. Goettingen.

[9] GREENE, D. H. \& KUTH, D., 1981. Mathematics for the Analysis of Algorithms, Boston: Birkhäuser.

[10] HAHN, H., 1988. Empirismus, Logik, Mathematik, Frankfurt: Suhrkamp.

[11] HILBERT, D., 1964. Über das Unendliche. In: Hilbertiana, Darmstadt.

[12] KANT, I., 1787. Critique of Pure Reason. English translation by Norman Kemp Smith, 1929. Palgrave Macmillan Pub.

[13] KATZ, J. J., 2004. Sense, Reference and Philosophy. Oxford University Press.

[14] KLEIN, S. B., 2014. The Two Selves, Oxford University Press

[15] KUHN, T. S., 1996. The Structure of Scientific Revolutions. University of Chicago Press.
[16] LAKATOS, I. (1970). Falsification and the methodology of science research programs. In Lakatos/Musgrave (Eds.), Criticism and the growth of knowledge. Cambridge UP.

[17] LEIBNIZ, G. W., 1685. The Art of Discovery. In: (W51) Leibniz: Selections. Edited by Philip P. Wiener. New York: Charles Scribner's Sons, 1951.

[18] LOVEJOY, A. O., 1964, The Great Chain of Being: A Study of the History of an Idea, Cambridge, Massachusetts: Harvard University Press.

[19] MASANI, P. R., 1990. Norbert Wiener 1894-1964. Basel: Birkhäuser Verlag.

[20] MAYR, E., 2001. What Evolution Is. New York: Basic Books.

[21] NEWTON, I., 1729. Mathematical Principles of Natural Philosophy. Oxford University.

[22] OTTE, M., 1994. Intuition and logic in mathematics. In: D.E. Robitaille, D. H. Wheeler and C. Kieran (eds.), Selected Lectures from the $7^{\text {th }}$ International Congress on Mathematical Education, Les Presses de 1'Université Laval, 271-284.

[23] OTTE, M., 2003. Complementarity, sets and numbers. Educational Studies in Mathematics 53, 203-228.

[24] OTTE, M. \& STEINBRING, H., 1977. Probleme der Begriffsentwicklung. Didaktik der Mathematik 1, 16-25.

[25] OTTE, M. \& LENHARD, J., 2010. Two Types of Mathematization. In Bart Van Kerkhove, Jonas De Vuyst and Jean Paul Van Bendegem, Philosophical perspectives on mathematical practice. (pp. 301-330). London: College Publications, 2010.

[26] PEIRCE, C. S. CP = Collected Papers of Charles Sanders Peirce, Volumes I-VI, ed. by Charles Hartshorne and Paul Weiß, Cambridge, Mass. (Harvard UP) 1931-1935, Volumes VII-VIII, ed. by Arthur W. Burks, Cambridge, Mass. (Harvard UP) 1958 (quoted by no. of volume and paragraph) NEM = Carolyn Eisele (ed.), The New Elements of Mathematics by Charles S. Peirce, Vol. I-IV, The Hague-Paris/Atlantic Highlands, N.J. (Mouton/Humanities Press)

[27] PLANCK, M., 1936. The Philosophy of Physics, W.W. Norton Co.

[28] POPPER, K., 1972. Objective Knowledge, Oxford University Press.

[29] QUINE, W. V. O., 1974. Roots of Reference. La Salle: Open Court.

[30] REICHENBACH, H., 1951. The Rise of Scientific Philosophy. Berkeley: University of California Press.

[31] RORTY, R., 1979. Philosophy and the Mirror of Nature. Princeton, NJ: Princeton University Press.

[32] RUCKER, R., 1982. Infinity and the Mind. Basel: Birkhäuser.

[33] RUSSELL, B., 1919. Introduction to Mathematical Philosophy. London: Routledge.

[34] SCHLICK, M., 1925. Epistemology \& Modern Physics. Garland Publishing Inc.

[35] SCHÜLING, H., 1969. Die Geschichte der axiomatischen Methode im 16. und beginnenden 17. Jahrhundert, Hildesheim. 
[36] SEARLE, J., 1980. Minds, Brains and Programs. In: Behavioral and Brain Sciences 3 (3). p. 417-457. Cambridge University Press.

[37] SHANE, E., 2014. Turner. New York: Parkstone Press.

[38] STEWART, M., 2006. The Courtier and the Heretic. New York: W. W. Norton.
[39] STOLZENBERG, G., 1980. Can an Inquiry into the Foundations of Mathematics tell us anything interesting about the Mind. In: P. Watzlawik (ed.) Invented Reality, W. W. Norton Inc., pp 257-308

[40] TUOMELA, R., 1973. Theoretical Concepts. Springer Wien.

[41] TURNER, M., 2014, The Origin of Ideas, Oxford University Press. 